\title{
RESEARCH
}

Open Access

\section{Altered levels of CSF proteins in patients with FTD, presymptomatic mutation carriers and non-carriers}

Julia Remnestål ${ }^{1,2 \dagger}$ D , Linn Öijerstedt ${ }^{2,3,4 \dagger}$, Abbe Ullgren ${ }^{2,3}$, Jennie Olofsson ${ }^{1,2}$, Sofia Bergström ${ }^{1,2}$, Kim Kultima ${ }^{5}$, Martin Ingelsson ${ }^{6}$, Lena Kilander ${ }^{6}$, Mathias Uhlén ${ }^{1,7}$, Anna Månberg ${ }^{1,2}$, Caroline Graff ${ }^{2,3,4^{*}+}$ and Peter Nilsson ${ }^{1,2^{*}+}$

\begin{abstract}
Background: The clinical presentations of frontotemporal dementia (FTD) are diverse and overlap with other neurological disorders. There are, as of today, no biomarkers in clinical practice for diagnosing the disorders. Here, we aimed to find protein markers in cerebrospinal fluid (CSF) from patients with FTD, presymptomatic mutation carriers and non-carriers.

Methods: Antibody suspension bead arrays were used to analyse 328 proteins in CSF from patients with behavioural variant FTD (bvFTD, $n=16$ ) and progressive primary aphasia (PPA, $n=13$ ), as well as presymptomatic mutation carriers (PMC, $n=16$ ) and non-carriers $(N C, n=8)$. A total of 492 antibodies were used to measure protein levels by direct labelling of the CSF samples. The findings were further examined in an independent cohort including 13 FTD patients, 79 patients with Alzheimer's disease and 18 healthy controls.

Results: We found significantly altered protein levels in CSF from FTD patients compared to unaffected individuals (PMC and NC) for 26 proteins. The analysis show patterns of separation between unaffected individuals and FTD patients, especially for those with a clinical diagnosis of bvFTD. The most statistically significant differences in protein levels were found for VGF, TN-R, NPTXR, TMEM132D, PDYN and NF-M. Patients with FTD were found to have higher levels of TN-R and NF-M, and lower levels of VGF, NPTXR, TMEM132D and PDYN, compared to unaffected individuals. The main findings were reproduced in the independent cohort.

Conclusion: In this pilot study, we show a separation of FTD patients from unaffected individuals based on protein levels in CSF. Further investigation is required to explore the CSF profiles in larger cohorts, but the results presented here has the potential to enable future clinical utilization of these potential biomarkers within FTD.
\end{abstract}

Keywords: Frontotemporal dementia, Cerebrospinal fluid, Biomarkers, Proteomics, Antibody suspension bead array

\footnotetext{
* Correspondence: caroline.graff@ki.se; https://www.ki.se/brainbank;

https://www.ki.se/en/nvs/caroline-graff-group; peter.nilsson@scilifelab.se

${ }^{+}$Caroline Graff and Peter Nilsson shared senior and corresponding authors.

${ }^{\dagger} J u l i a$ Remnestål and Linn Öijerstedt shared first author.

${ }^{2}$ Swedish FTD Initiative, Stockholm, Sweden

'Division of Affinity Proteomics, Department of Protein Science, KTH Royal Institute of Technology, SciLifeLab, Tomtebodavägen 23 A, Alpha 2, 17165 Solna, Stockholm, Sweden

Full list of author information is available at the end of the article
}

(c) The Author(s). 2020 Open Access This article is licensed under a Creative Commons Attribution 4.0 International License, which permits use, sharing, adaptation, distribution and reproduction in any medium or format, as long as you give appropriate credit to the original author(s) and the source, provide a link to the Creative Commons licence, and indicate if changes were made. The images or other third party material in this article are included in the article's Creative Commons licence, unless indicated otherwise in a credit line to the material. If material is not included in the article's Creative Commons licence and your intended use is not permitted by statutory regulation or exceeds the permitted use, you will need to obtain permission directly from the copyright holder. To view a copy of this licence, visit http://creativecommons.org/licenses/by/4.0/ The Creative Commons Public Domain Dedication waiver (http://creativecommons.org/publicdomain/zero/1.0/) applies to the data made available in this article, unless otherwise stated in a credit line to the data. 


\section{Background}

Frontotemporal dementia (FTD) is one of the most common forms of early onset dementia. The clinical presentations are diverse and overlap with other psychiatric and neurological disorders [1]. The major phenotypes are behavioural variant FTD (bvFTD) and primary progressive aphasia (PPA). Patients with bvFTD present personality changes such as inappropriate behaviour, impaired judgement and loss of empathy. PPA can be further divided into progressive non-fluent aphasia (PNFA), in which patients have effortful speech with phonetic errors, and semantic dementia (SD) in which patients have fluent speech but impaired single-word comprehension [1, 2]. In addition, approximately $15 \%$ of FTD patients develop amyotrophic lateral sclerosis (ALS) and other motoric symptoms [3]. This phenotypic heterogeneity and lack of objective diagnostic tests may result in misdiagnosis and incorrect care of patients and their families $[4,5]$.

A family history of dementia is found in up to half of patients with FTD [6]. Several genetic variants are known to cause FTD, and are most frequently identified in the genes C9orf72, progranulin (GRN) and microtubule-associated protein tau $(M A P T)$ [7-11]. In Sweden, the frequency of the C9orf72 repeat expansion mutation is particularly high $[12,13]$. The pathogenic mutations are weakly associated with the different FTD phenotypes [14]. Genetic testing is useful for diagnostic confirmation of a genetic cause of FTD but has limited value for prognosis of age at onset or phenotype in presymptomatic individuals. Numerous studies have investigated potential protein biomarkers for FTD in cerebrospinal fluid (CSF) [15-18] and one promising candidate is neurofilament light chain (NF-L). In 2016, Meeter et al. showed that CSF NF-L is elevated in patients with FTD compared to controls and suggested that the levels correlate to disease severity [16, 19]. However, elevated levels of CSF NF-L have also been found in several other neurodegenerative diseases and are thus not specific for FTD [20, 21].

This far, most studies have focused on analysing single candidate proteins. Here, we utilize antibody based suspension bead arrays that enabled a high throughput multiplex screening of 328 proteins in 53 CSF samples from FTD patients, presymptomatic mutation carriers and non-carriers from Sweden. We aimed to find differences in protein profiles between patients, presymptomatic mutation carriers and non-carriers to discover novel protein biomarkers for further clinical validation.

\section{Methods}

\section{Participants}

The exploratory cohort 1 was recruited at the Memory clinic at Karolinska University Hospital and consisted of both patients diagnosed with FTD and unaffected subjects enrolled in the GENFI-study (GENetic Frontotemporal Dementia Initiative): 29 were diagnosed with FTD, between 1997 and 2016, according to the criteria by Rascovsky et al. 2008 or Gorno-Tempini et al 2011 [1, 2] and 24 were clinically unaffected participants from the GENFI-study (Table 1) [22, 23]. All the unaffected participants were at $50 \%$ risk of FTD due to a confirmed pathogenic mutation in a first degree relative. Throughout the text, "unaffected individuals" will be used as a

Table 1 Cohort demographics

\begin{tabular}{|c|c|c|c|c|}
\hline \multicolumn{5}{|l|}{ Cohort 1} \\
\hline & $\begin{array}{l}\mathbf{N C} \\
(n=8)\end{array}$ & $\begin{array}{l}\text { PMC } \\
(n=16)\end{array}$ & $\begin{array}{l}\text { PPA } \\
(n=13)\end{array}$ & $\begin{array}{l}\text { bvFTD } \\
(n=16)\end{array}$ \\
\hline Age, median years (range) ${ }^{a}$ & $52(24-65)$ & $53(31-71)$ & $65(52-79)$ & $61(40-78)$ \\
\hline Female, N (\%) & $4(50)$ & $10(62)$ & $8(57)$ & $6(37)$ \\
\hline Age at onset, median years (range) & - & - & $63(50-78)$ & $59(39-77)$ \\
\hline Years to expected onset ${ }^{\mathrm{b}}$, median years (range) & - & $8(-24,+3)$ & - & - \\
\hline \multicolumn{5}{|l|}{ Mutation, N (\%) } \\
\hline C9orf72 & - & $8(50)$ & 0 & $2(13)$ \\
\hline GRN & - & $8(50)$ & $1(8)$ & - \\
\hline VCP & - & - & - & $1(6)$ \\
\hline Cohort 2 & $\begin{array}{l}\text { Control } \\
(n=18)\end{array}$ & $\begin{array}{l}\text { FTD }^{c} \\
(n=13)\end{array}$ & $\begin{array}{l}\text { AD } \\
(n=79)\end{array}$ & \\
\hline Age, median years (range) ${ }^{d}$ & $81(74-86)$ & $68(50-83)$ & $72(54-88)$ & \\
\hline Female, N (\%) & $10(56)$ & $4(31)$ & $49(62)$ & \\
\hline
\end{tabular}

NC Non carriers, PMC Presymptomatic mutation carriers, PPA Primary progressive aphasia, bvFTD - behavioural variant FTD, $A D$ Alzheimer's disease

${ }^{a}$ Differences in age were found between PPA and unaffected individuals (ANOVA, $p=0.001$, pairwise post hoc test PPA vs NC, $p=0.01$, PPA vs PMC, $p=0.01$ ).

Differences where found between FTD as a whole group and unaffected individuals (t-test, $p<0.001$ )

${ }^{b}$ Difference between the subjects age at sampling and the mean age at onset in their family

c Clinical phenotype: 7 bvFTD and 5 SD

${ }^{\mathrm{d}}$ Differences in age were found between controls and FTD/AD (ANOVA, $p<0.001$, pairwise post hoc test controls vs FTD, $p<0.001$, controls vs AD, $p<0.001$ ) 
collective term for presymptomatic mutation carriers and non-carriers. The study was approved by the Regional Ethical Review Board, Stockholm, Sweden (registration numbers: 2017/834-31/1, 2012/1611-31/ 3, 2013/1563-32, 2017/2097-32).

An independent cohort from Uppsala University Hospital (cohort 2) consisting of 13 patients diagnosed with FTD, 79 patients diagnosed with Alzheimer's disease (AD) and 18 healthy individuals were used to replicate the main findings in the cohort collected at the Karolinska University Hospital Memory clinic (Table 1). The study was approved by the Regional Ethical Review Board in Uppsala, Sweden (registration numbers: 2005-244, Ö 48-2005; 2005-11-02, 2006-01-30, 2011/044; 2011-02-23).

All participants gave informed consent to research, including DNA and CSF sampling. Detailed information about patient recruitment and sample collection can be found in Supplementary Materials and Methods.

\section{Genetic screening}

FTD patients recruited at the Karolinska University Hospital Memory clinic were screened for mutations in C9orf72, GRN and MAPT $(n=25)$ or by whole genome sequencing $(n=4)$ (see Supplementary Materials and Methods). Unaffected subjects were screened for the mutation segregating in the family using Sangersequencing (for MAPT and GRN) or repeat primed PCR (for C9orf72 repeat expansion). Thus, the mutation status was known in cohort 1.

\section{Protein profiling}

Antibody suspension bead arrays were used to explore the protein profiles in human CSF. A total of 328 proteins, targeted by 492 antibodies, were included in the experimental analysis. Creation of the suspension bead array was done by immobilizing antibodies onto magnetic, colour coded carboxylated beads as described previously [24-27]. Fifteen $\mu \mathrm{l}$ of each CSF sample was diluted, labelled with biotin and detection was enabled by a streptavidin coupled fluorophore, reported as median fluorescence intensity (MFI) from at least 30 beads per bead identity and sample (see Supplementary Materials and Methods).

\section{Validation of NF-M antibodies}

To ensure that the antibodies HPA023138 and HPA022845 captured neurofilament medium polypeptide (NF-M) in the studied sample material, a sandwich assay directed toward NF-M was developed according to a previously published workflow [28] (see Supplementary Materials and Methods).

\section{Data processing and statistical analysis}

All data analysis and data visualizations were performed using the open source software R version 3.5.1 [29].

\section{Demographics}

Tests of normality were performed using Shapiro-Wilk test (age, age at onset, years to expected onset). ANOVA with Bonferroni post hoc tests were used for assessing differences in age between patients and unaffected individuals. Due to a violation of the assumption of normality, Mann-Whitney $U$ test was used when assessing the variable age at onset. When assessing sex differences, Fischer's exact test was used as the expected values was $<5$ in more than $20 \%$ of the contingency cells. $P$-values of $<0.05$ were considered significant.

\section{Analysis of protein profiles}

Differences in protein levels between patients with FTD and unaffected individuals were investigated using principal component analysis (PCA) from a set of antibodies with intra-assay coefficient of variance $(\mathrm{CV})<10 \%$ and inter-assay rho $>0.8$. To avoid bias from multiple antibodies targeting the same protein, one antibody was selected for each target. All protein values were univariance scaled and centered as in R function prcomp default. The antibody selection for the PCA analysis was made based on the highest degree of technical validation within the Human protein atlas project (HPA, www.proteinatlas.org). All group comparisons were made using the Mann-Whitney $U$ test and all $p$-values were false discovery rate (FDR) adjusted by the Benjamini-Hochberg procedure for multiple comparisons [30]. Adjusted pvalues of $<0.01$ were considered significant. Generalized linear models for gamma distributed variables were performed on log transformed data to examine effects of age at sampling on protein level differences between the studied groups. Two hierarchical clustering models were made using complete linkage. The first one using the 10 first principal components from the PCA and the second one using intensity levels of a selected set of proteins. The clustering was presented as dendrograms using a cut off of four clusters, based on the number of subject groups. All additional protein or antibody correlations were calculated using Spearman's rho statistics.

\section{Results}

\section{Demographics}

Cohort 1 consisted of 29 patients diagnosed with FTD and 24 unaffected individuals with a $50 \%$ risk of genetic FTD. Of the 29 FTD patients, sixteen fulfilled criteria for bvFTD, eight for PNFA and four for SD. Four of the patients displayed symptoms of motor neuron disease. One patient with PPA could not be subclassified as neither PNFA nor SD. This individual had anomic aphasia and 
alexia with agraphia but did not fulfil criteria for SD. Magnetic resonance imaging showed atrophy of the left temporal cortex. CSF total-tau (291 ng/L), phospho-tau $(50 \mathrm{ng} / \mathrm{L})$ and Amyloid beta $42(489 \mathrm{ng} / \mathrm{L})$ were within normal range. Four of the FTD patients were found to have a pathogenic mutation, two with the C9orf72 repeat expansion mutation, one with a GRN mutation and one with a valosin containing protein $(V C P)$ mutation.

Among the 24 unaffected individuals, 8 were nonmutation carriers (NC), 8 were C9orf72 mutation carriers and 8 were GRN mutation carriers. These mutation carriers are denoted as presymptomatic mutation carriers, (PMC) (Table 1). When comparing the mean age at sampling in the four groups (NC, PMC, bvFTD and PPA), differences were only found between PPA and unaffected (PPA, 65 years; PMC, 53 years; NC, 52 years; ANOVA, $p=0.001$, pairwise post hoc test PPA vs NC, $p=0.01$ and PPA vs PMC, $p=0.01$ ). Differences in age were found between FTD as a whole group and unaffected individuals (FTD, 64 years; unaffected, 53 years; t-test, $p<0.001)$. The sex distribution was not statistically different between the four groups (Fisher's exact test, $p=0.49$ ). Patients with PPA had a later age at onset compared to bvFTD (mean 63 vs 59 years).

Cohort 2 consisted of 13 patients diagnosed with FTD (7 with bvFTD and 5 with SD), 79 patients diagnosed with $\mathrm{AD}$ and 18 healthy individuals. When comparing the mean age at sampling in the three groups, differences were found between controls and FTD/AD (ANOVA, $p<0.001$, pairwise post hoc test controls vs FTD, $p<0.001$, controls vs AD, $p<0.001$ ) (Table 1 ).

\section{Analysis of protein profiles}

A principal component analysis of 70 proteins (targeted by the most robust antibodies, which fulfilled intra-assay
$\mathrm{CV}<10 \%$ and inter-assay rho $>0.8)$ showed that the majority of the distribution of differences in protein levels could be explained by principal components 1 to 10 (90\%). Figure 1a illustrates differences in protein levels between patients with FTD, PMC and NC. Unaffected individuals mainly cluster at the bottom left and bvFTD patients at the upper right while PPA patients are scattered around the plot.

Differences between all FTD patients (bvFTD and PPA) and unaffected individuals were further visualized by hierarchical clustering of PC 1 to 10 . Two major clusters were revealed (Fig. 1b): one including 12/16 (75\%) of the bvFTD patients and 7/13 (54\%) of the PPA patients (Cluster 1), and the other including all $\mathrm{NC}$ and the majority (56\%) of PMC (Cluster 2). A third minor cluster was also observed consisting of three PPA patients, three bvFTD patients and a single PMC (Cluster 3 ). Two individuals (one PMC and one PPA) made one separate cluster (Cluster 4).

\section{Protein level differences between bvFTD, PPA, PMC and NC} The PCA indicated differences in protein profiles between FTD patients and unaffected individuals. Comparisons were also made for each protein separately $(n=70)$, illustrated in Fig. 2 and Supplementary Table 1. Statistically significant differences in protein levels (FDR adjusted $p<0.01$ ) between FTD patients and unaffected individuals were found for 26 proteins (purple and red points). Nine of the 26 proteins showed differences with an FDR adjusted $p$-value below 0.001: neurosecretory protein VGF (VGF), neuronal pentraxin receptor (NPTXR), transmembrane protein 132D (TMEM132D), prodynorphin (PDYN), neurofilament medium polypeptide (NF-M) (with two independent antibodies), tenascin-R (TN-R), neuronal pentraxin-1 (NP1),

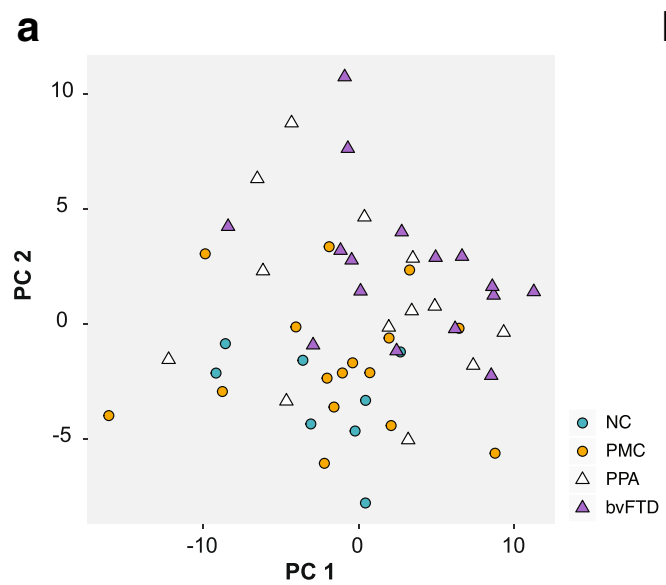

b

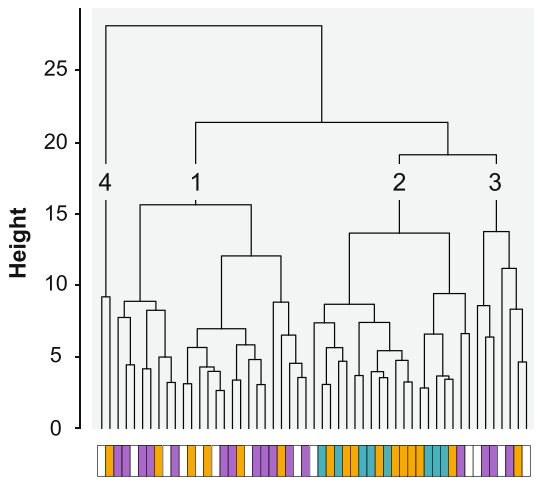

Fig. 1 PCA and cluster dendrogram. a PCA plot of principal component 1 and 2. Unaffected individuals are shown as circles and FTD patients as triangles. $\mathbf{b}$ Cluster dendrogram of principal component 1 to 10. The four groups are indicated by the coloured bar and numbers have been added to each cluster for clarification. NC - Non-carriers, PMC - Presymptomatic mutation carriers, PPA - Primary progressive aphasia, bvFTD Behavioural variant FTD 


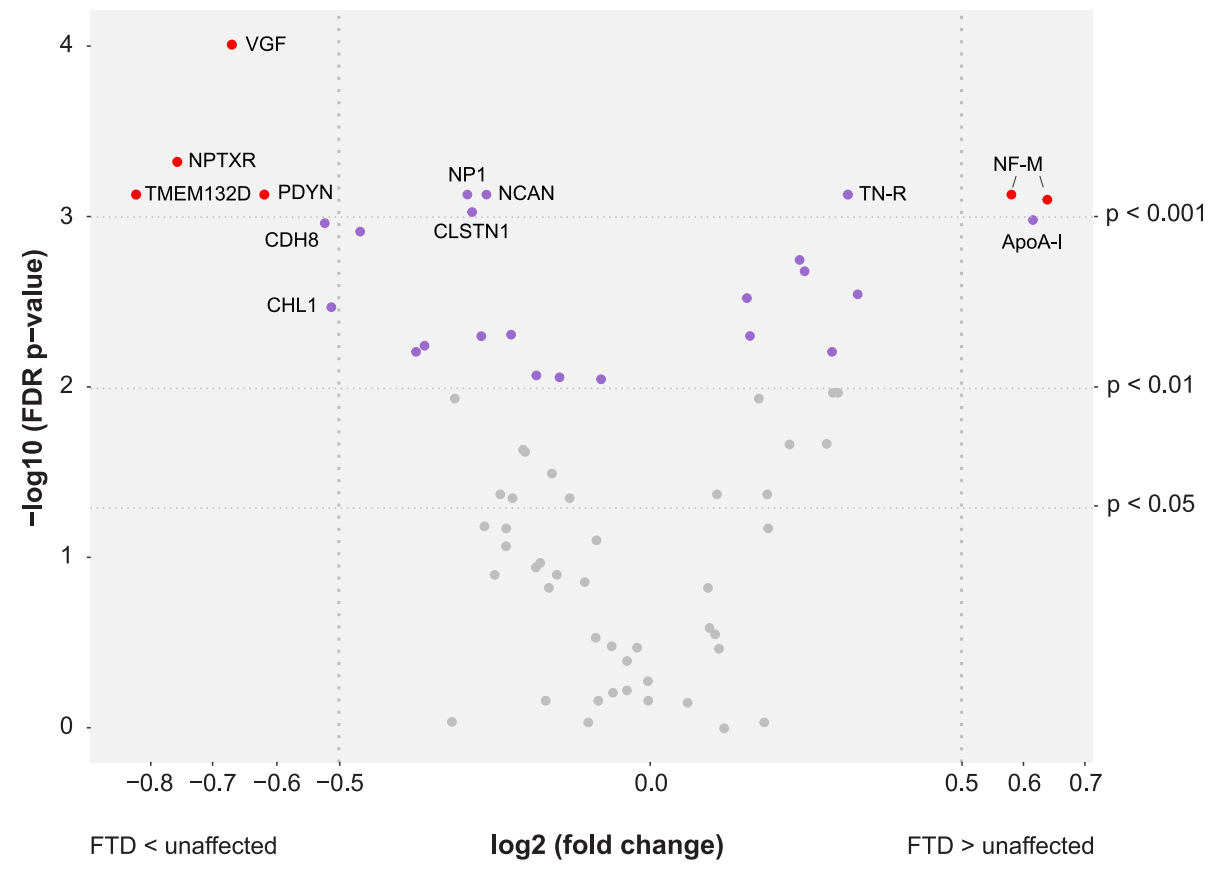

Fig. 2 Volcano plot of analysed proteins $(n=70)$. Differences in protein levels between FTD patients and unaffected individuals displayed by $\log 2$ (fold change) and significance level displayed as $-\log 10(p)$. All proteins with significant differences (FDR adjusted $p<0.01$ ) are displayed in purple. Proteins highlighted with gene names have a $p<0.001$ or an absolute log2(fold change) $>0.5$ (corresponding to a fold change $<0.7$ or $>1.4$ ). The five proteins with both a $p<0.001$ and an absolute $\log 2$ (fold change) $>0.5$ are displayed in red

neurocan core protein (NCAN) and calsyntenin-1 (CLSTN1). An absolute log2 fold change larger than 0.5 (corresponding to a fold change $<0.7$ or $>1.4$ ) was observed for eight proteins: TMEM132D, NPTXR, VGF, NF-M, PDYN, apolipoprotein A-I (ApoA-I), cadherin-8 (CDH8) and neural cell adhesion molecule L1-like protein (CHL1). The five proteins VGF, NPTXR, TMEM132D, PDYN and NF-M showed both an absolute fold change $>0.5$ and statistically significant differences (FDR adjusted $p<0.001$ ) (Fig. 2, red points, Fig. 3a-e). Nine of the 26 proteins were elevated in FTD patients compared to unaffected individuals, while lower levels were observed for the other 17 proteins. Generalized linear models showed that age had a significant effect $(p<0.05)$ on the differences between the two groups for eight proteins; CLSTN1, Peptidyl-glycine alpha-amidating monooxygenase, ApoAI, Leucine-rich alpha-2-glycoprotein (LRG), Alpha-1antichymotrypsin (ACT), Inter-alpha-trypsin inhibitor heavy chain $\mathrm{H} 1$, Oligodendrocyte-myelin glycoprotein and Phosphoinositide-3-kinase-interacting protein 1 (Table 2 and Supplementary Table 2).

The protein levels were further compared between bvFTD, PPA, PMC and NC. Statistically significant differences (here defined as FDR adjusted $p<0.001$ ) in protein levels were found for six proteins between bvFTD and PMC and for fifteen proteins between bvFTD and NC (Table 2). No significant differences were observed when comparing $\mathrm{NC}$ with $\mathrm{PMC}$, or when comparing
PPA to bvFTD. The most statistically significant differences between the subgroups (bvFTD vs NC and bvFTD vs PMC) were found for the proteins VGF and TN-R. VGF was found in lower levels in bvFTD compared to NC and PMC while TN-R showed the opposite trend (Fig. 3a and f). NF-M showed results similar to that of TNR, with higher levels in FTD patients compared to NC and PMC (Fig. 3e). The proteins NPTXR, TMEM132D and PDYN all displayed lower levels in FTD patients compared to NC and PMC (Fig. 3b-d). A visualisation of the comparisons across the different subgroups for every additional protein in Table 2 can be found in Supplementary Figure 1. Generalized linear models showed that age had a significant effect $(p<0.05)$ on group differences for seven proteins, the same as for the analysis between FTD and unaffected individuals except CLSTN1 (see above).

\section{Combining protein levels of VGF, TN-R and NF-M}

As previously stated, VGF and TN-R were the two proteins for which the subgroup analyses showed the lowest $p$-values (bvFTD vs NC p-values 0.002 and 0.003 respectively and bvFTD vs PMC p-values 0.0008 and 0.002 respectively) (Table 2). However, in the comparison between all patients with FTD and unaffected individuals, NF-M was one of the proteins with lowest p-value (0.0007) together with a high $\log 2$ fold change (0.58). Moreover, NF-M was the only protein with a p-value < 

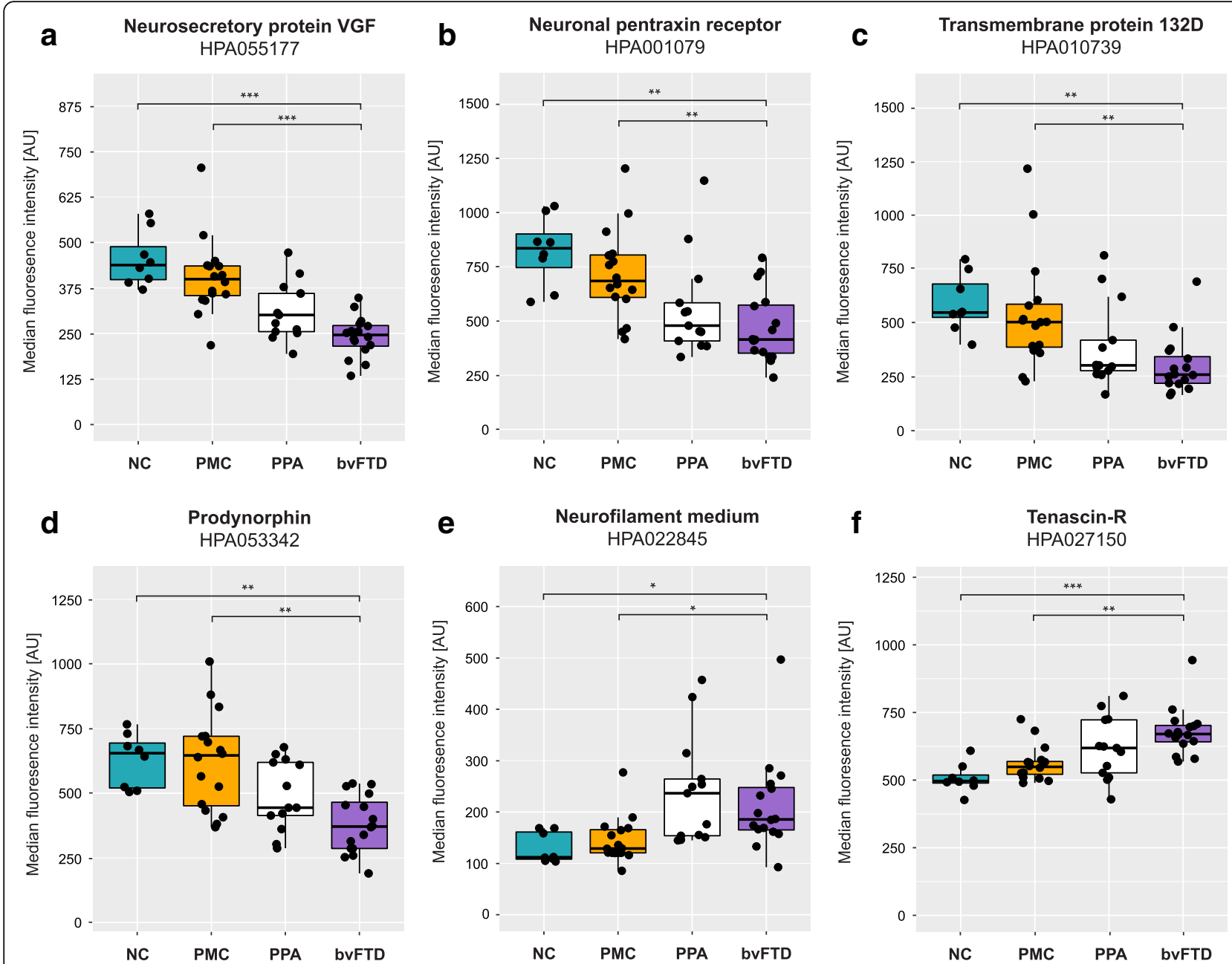

Fig. 3 CSF levels in the different clinical subgroups (NC, PMC, PPA and bvFTD). (a) neurosecretory protein VGF (VGF), (b) neuronal pentraxin receptor (NPTXR), (c) transmembrane protein 132D (TMEM132D), (d) prodynorphin (PDYN), (e) neurofilament medium polypeptide (NF-M) and (f) tenascin-R (TN-R). Stars indicate significant differences, ${ }^{*} p<0.05,{ }^{* *} p<0.01$ and ${ }^{* * *} p<0.001 \mathrm{NC}-$ Non-carriers, PMC - Presymptomatic mutation carriers, PPA - Primary progressive aphasia, bvFTD - Behavioural variant FTD

0.001 and $\log 2$ fold change $>0.5$ that displayed higher levels in FTD compared to unaffected individuals (Fig. 2, Supplementary Table 1). The results on NF-M are highly interesting as they are in agreement with previously published results on the closely related protein neurofilament light chain [19]. Hence, the intensity levels of NF$\mathrm{M}, \mathrm{VGF}$ and TN-R were analysed for their combined ability to separate bvFTD, PPA, PMC and NC (Fig. 4). FTD patients could be separated from NC and PMC, as seen in Fig. 4a. Similarly, hierarchical clustering of VGF, TN-R and NF-M protein levels showed that FTD patients and unaffected individuals primarily clustered separately (Fig. 4b). The majority (81\%) of the bvFTD patients clustered together (Cluster 1 ) while most of the PMC (81\%) and NC (100\%) individuals clustered separately from the patients (Cluster 2 and 4). Patients with PPA were spread out across three clusters, similar to the result from the PCA.

\section{Characterization in an independent cohort}

To investigate whether the differences in protein levels between FTD patients and unaffected individuals (Table 2) could be replicated in another sample material, protein levels were analysed in a second cohort (Table 1). This cohort also included samples from patients with AD to allow comparison to another type of neurodegenerative disease. Results could be replicated in the second cohort for VGF, NPTXR, PDYN, NF-M, TN-R and five other proteins, but not for TMEM132D (Fig. 5, Table 2 and Supplementary Table 3). In addition, a significant difference in protein levels was found between FTD and AD for TN-R and NFM (only one antibody, HPA023138, Supplementary Table 3), but not for VGF, NPTXR or PDYN. The FTD patients displayed higher levels of both TN-R and NF-M compared to $\mathrm{AD}$. The generalized linear models showed that age had a significant effect $(p<0.05)$ on group differences for three proteins in the second 
Table 2 List of proteins with significant differences in protein profiles. Sorted by p-values for comparison of bvFTD and NC (lowest to highest)

\begin{tabular}{|c|c|c|c|c|c|c|c|}
\hline Protein name & Short name & Uniprot ID & Antibody & bvFTD vs NC & bvFTD vs PMC & $\begin{array}{l}\text { FTD vs } \\
\text { unaffected }\end{array}$ & $\begin{array}{l}\text { Direction of } \\
\text { change }^{c}\end{array}$ \\
\hline Neurosecretory protein VGF & VGF & 015240 & HPA055177 & 0.0002 & 0.0003 & $0.0001^{b}$ & $\downarrow$ \\
\hline Tenascin- $R$ & TN-R & Q92752 & HPA027150 & 0.0008 & 0.002 & $0.0007^{b}$ & $\uparrow$ \\
\hline Neuronal pentraxin receptor & NPTXR & 095502 & HPA001079 & 0.003 & 0.008 & $0.0005^{\mathrm{b}}$ & $\downarrow$ \\
\hline Transmembrane protein 132D & TMEM132D & Q14C87 & HPA010739 & 0.003 & 0.008 & 0.0007 & $\downarrow$ \\
\hline Prodynorphin & PDYN & P01213 & HPA053342 & 0.003 & 0.006 & $0.0007^{b}$ & $\downarrow$ \\
\hline Neurocan core protein & NCAN & 014594 & HPA058000 & 0.003 & 0.006 & $0.0007^{b}$ & $\downarrow$ \\
\hline Calsyntenin-1 & CLSTN1 & 094985 & HPA012749a & 0.003 & 0.01 & $0.0009^{b}$ & $\downarrow$ \\
\hline Cadherin-8 & $\mathrm{CDH} 8$ & P55286 & HPA014908 & 0.003 & 0.01 & 0.001 & $\downarrow$ \\
\hline Neural cell adhesion molecule L1-like protein & CHL1 & 000533 & HPA003345 & 0.003 & 0.02 & $0.003^{b}$ & $\downarrow$ \\
\hline Rabphilin-3A & $\mathrm{RPH} 3 \mathrm{~A}$ & Q9Y2J0 & HPA002475 & 0.004 & 0.01 & 0.001 & $\downarrow$ \\
\hline Peptidyl-glycine alpha-amidating monooxygenase & PAM & P19021 & HPA042260 & 0.004 & 0.02 & $0.005^{b}$ & $\downarrow$ \\
\hline Neuronal pentraxin-1 & NP1 & Q15818 & HPA077062 & 0.006 & 0.02 & 0.0007 & $\downarrow$ \\
\hline $\begin{array}{l}\text { von Willebrand factor C domain-containing } \\
\text { protein 2-like }\end{array}$ & WWC2L & B2RUY7 & HPA059414 & 0.006 & 0.01 & 0.003 & $\uparrow$ \\
\hline Tripeptidyl-peptidase 1 & TPP-1 & 014773 & HPA037709 & 0.008 & 0.02 & 0.002 & $\uparrow$ \\
\hline Amyloid-like protein 1 & APLP-1 & P51693 & HPA028971 & 0.008 & 0.05 & 0.009 & $\downarrow$ \\
\hline Apolipoprotein A-I & ApoA-I & P02647 & HPA046715 & 0.01 & 0.04 & 0.001 & $\uparrow$ \\
\hline Neurofilament medium polypeptide & NF-M & P07197 & HPA022845 & 0.02 & 0.02 & $0.0007^{b}$ & $\uparrow$ \\
\hline Neurofilament medium polypeptide & NF-M & P07197 & HPA023138 & 0.02 & 0.02 & $0.0008^{b}$ & $\uparrow$ \\
\hline Leucine-rich alpha-2-glycoprotein & LRG & P02750 & HPA001888 & 0.02 & 0.03 & 0.002 & $\uparrow$ \\
\hline Alpha-1-antichymotrypsin & $\mathrm{ACT}$ & P01011 & HPA000893 & 0.02 & 0.03 & 0.003 & $\uparrow$ \\
\hline UPF0606 protein KIAA1549L & KIAA1549L & Q6ZVL6 & HPA051594 & 0.02 & 0.02 & 0.005 & $\downarrow$ \\
\hline Inter-alpha-trypsin inhibitor heavy chain $\mathrm{H} 1$ & $\mathrm{ITI}-\mathrm{HCl}$ & P19827 & HPA042049a & 0.02 & 0.03 & 0.005 & $\uparrow$ \\
\hline Oligodendrocyte-myelin glycoprotein & OMG & P23515 & HPA008206 & 0.02 & 0.02 & $0.006^{b}$ & $\downarrow$ \\
\hline Neuronal cell adhesion molecule & $\mathrm{Nr}-\mathrm{CAM}$ & Q92823 & HPA061433 & 0.02 & 0.02 & 0.006 & $\downarrow$ \\
\hline TAR DNA-binding protein 43 & TDP-43 & Q13148 & HPA070770 & 0.02 & 0.01 & 0.006 & $\uparrow$ \\
\hline Brevican core protein & BEHAB & Q96GW7 & HPA007865 & 0.06 & 0.02 & 0.008 & $\downarrow$ \\
\hline Phosphoinositide-3-kinase-interacting protein 1 & PIK3IP1 & Q96FE7 & HPA007353 ${ }^{\mathrm{a}}$ & 0.08 & 0.04 & 0.009 & $\downarrow$ \\
\hline
\end{tabular}

cohort, ACT, LRG and TAR DNA-binding protein 43 (Supplementary Table 2 and Supplementary Table 3).

\section{Validation of NF-M antibodies}

Since the neurofilament chains contain common domains and sequences, we wanted to confirm that the anti NF-M antibodies did selectively bind NF-M. This was examined by development of sandwich assays using several combinations of antibodies targeting NF-M, NFL and NF-H (Supplementary Table 4). Results showed that antibody HPA022845 could successfully detect NF$\mathrm{M}$ in combination with the two independent antibodies 20,664-1-AP and 13-0700 (Supplementary Figure 2A-B, for correlation between the sandwich assays see Supplementary Figure 3). In addition, HPA023138 also detected NF-M in combination with a third antibody: 34-1000 (Supplementary Figure 2C). Comparison to single-binder data showed strong correlation (rho $>0.82, p<1 \mathrm{E}^{-6}$ ) between the two assay formats (Supplementary Figure 2D-F). Correlations between different NF-M assays are found in Supplementary Figure 3.

\section{Discussion}

In this study, we found altered protein levels in CSF from FTD patients compared to unaffected individuals. Both principal component analysis and analysis of single 


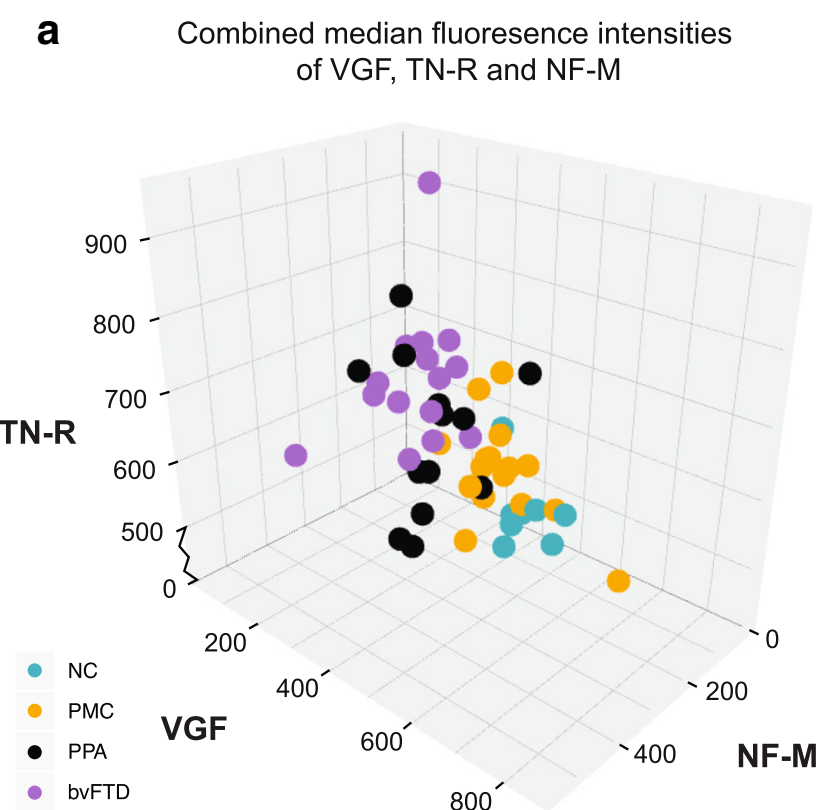

\section{b Cluster dendrogram of VGF, TN-R and NF-M
median fluoresence intensities}

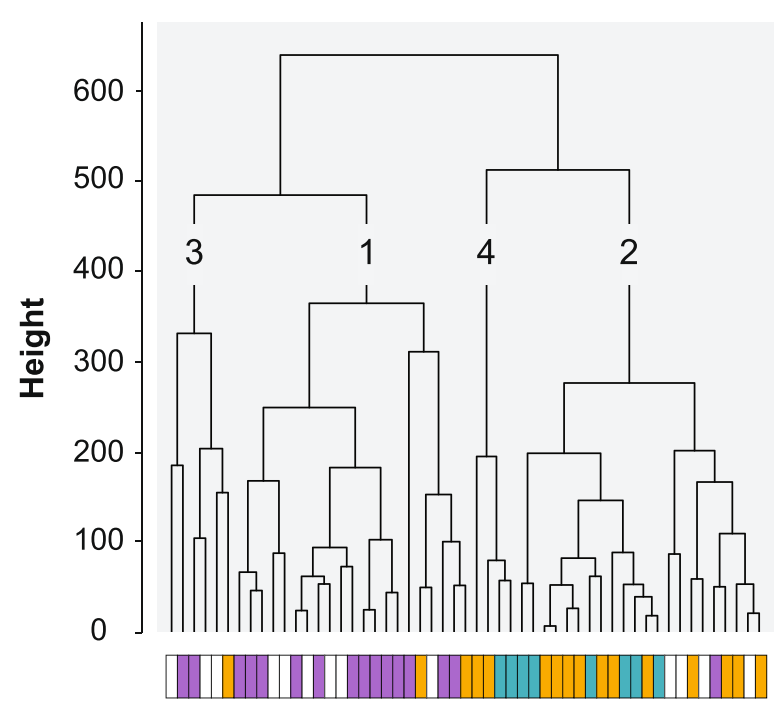

Fig. 4 Patient group separations and clustering by VGF, TN-R and NF-M. a Separation of FTD patients and unaffected individuals by combining levels of VGF, TN-R and NF-M. NC (turquoise), PMC (yellow), PPA (black for contrast) and bvFTD (purple). b Hierarchical clustering of VGF, TN-R and NF-M levels similarly show that FTD patients and unaffected individuals primarily clustered separately. The four groups are indicated by the colored bar, NC (turquoise), PMC (yellow), PPA (white) and bvFTD (purple) and numbers have been added to each cluster for clarification. NC Non-carriers, PMC - Presymptomatic mutation carriers, PPA - Primary progressive aphasia, bvFTD - Behavioural variant FTD

protein levels show patterns of separation between unaffected individuals and FTD patients, especially for those with a clinical diagnosis of bvFTD. In total, the levels of 26 proteins in FTD patients were found to be significantly different $(p<0.01)$ when compared to unaffected individuals. When comparing the subgroups NC, PMC, PPA and bvFTD, the most statistically significant differences in protein levels were found for VGF, TN-R, NPTXR, TMEM132D, PDYN and NF-M, none of which were affected by age.

Principal component analysis and hierarchical clustering was used to visualize overall differences on CSF protein levels between the studied individuals. The distribution pattern revealed that the unaffected individuals and FTD patients cluster differently, although with an overlap between the groups. Of the 26 proteins with significantly different levels in FTD patients compared to unaffected individuals, eight displayed an absolute $\log 2$ fold change larger than 0.5 , also highlighting the overlap between the groups. However, when dividing patients into bvFTD and PPA, and unaffected individuals into PMC and NC, we observed more distinct differences.

A total of 15 proteins showed significant differences between bvFTD and NC and six proteins were significantly different when comparing bvFTD with PMC (Table 2). The direction of each difference was the same when comparing to both $\mathrm{NC}$ and PMC, but the PMC protein levels were in general closer to those of bvFTD patients. This trend might illustrate an altered protein profile in the preclinical stage of FTD, similar to what is seen in presymptomatic mutation carriers in genetic $\mathrm{AD}$ [31]. The nine proteins that showed a difference between bvFTD and NC, but not between bvFTD and PMC might be important for monitoring the transition to an early disease stage which can be useful for estimation of time to clinical onset. However, the sample size is low, and the PMCs are of different ages, thus with a variable expected time to symptom onset. In the univariate analyses, all PMC individuals are considered as one group when compared to both NC and FTD cases. The differences in time to expected onset within the PMC group may explain why the differences between PMC and NC, as well as bvFTD and PMC for the nine proteins, did not reach statistical significance. On the other hand, the observation that PMC and NC clustered together in the multivariate analysis could imply that a group of proteins, such as the one studied here, will be useful for monitoring the conversion from PMC to FTD. The separation seen between bvFTD and PMC indicates that the protein profile changes at conversion to dementia. This agrees with previous studies on for example NF-L, which is suggested to be a diagnostic, as well as a disease staging marker for FTD [19].

No distinct differences between patients with bvFTD and PPA could be seen neither in the PCA nor the univariate analysis. The large range in protein levels among 


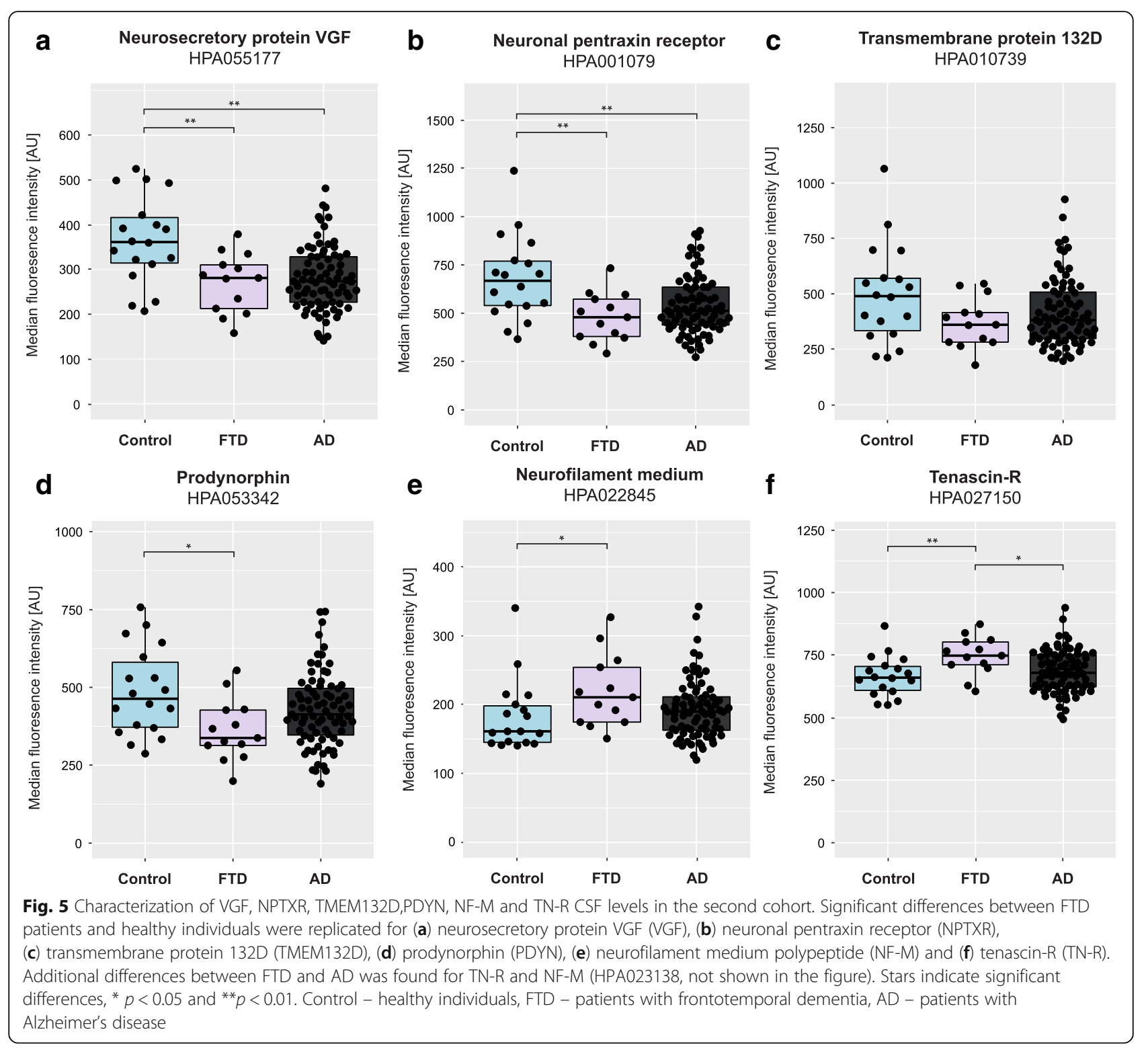

PPA patients is most likely a contributing factor to the absence of significant differences between PPA and $\mathrm{NC}$ / PMC. If this variability is due to the small sample size or in fact reflects a protein heterogeneity in the aphasia phenotype, as could be interpreted by the PCA, has to be further explored.

The most significant differences between bvFTD, NC and PMC were seen for VGF and TN-R. To further examine the protein profiles, all proteins in Table 2 were analysed in a second cohort. The second cohort consisted of both patients with FTD and AD to enable comparisons between different types of neurodegenerative disease. The results from the initial screening could be replicated for ten proteins, although with modest differences. We also found significant differences in TN-R and NF-M levels between FTD and AD patients, suggesting that TN-R and NF-M could be used not only as general markers for neurodegeneration, but more specifically have the potential to separate between different pathologies. However, the differences observed in our study are relatively small and would need to be explored further before their potential can be determined.

VGF is a neuropeptide precursor believed to be important for dendritic growth and neuronal survival [32, 33]. Lower CSF levels of VGF in FTD patients, as seen in our study, was recently demonstrated using mass spectrometry [34-36]. Van der Ende et al. (2019) identified several proteins in CSF that differed between genetic FTD and controls of which seven were selected for validation by parallel reaction monitoring. VGF was found in lower levels in FTD due to GRN mutations, compared to controls. Although reaching statistical significance, VGF 
alone is not enough to distinguish FTD from other dementias as both our own and former studies have shown decreased levels in CSF from AD patients as well [3639]. TN-R is an extracellular matrix protein expressed by oligodendrocytes and neurons [40,41]. It is thought to have multiple functions within the central nervous system such as regulation of synaptic plasticity, cell migration and adhesion $[42,43]$. Downregulation of hippocampal TN-R was observed in a small set of individuals with AD, compared to age-matched controls by Manavlan et al. (2013) [44] but this is to our knowledge the first study investigating $\mathrm{TN}-\mathrm{R}$ as a potential biomarker for FTD. TN-R deficient mice display abnormal behaviours and motor coordination $[45,46]$ which indicates that TN-R is important for maintaining the normal cognitive functions.

In our study, NF-M was found at increased levels in patients which is similar to what has previously been observed for NF-L, with higher levels in FTD patients compared to unaffected individuals [19]. NF-M is approximately twice the size of its well-studied sibling, and assembles into structural filaments together with NF-L and neurofilament heavy chain (NF-H) [47]. The intracellular ratio of the neurofilament isoforms is known [48] but the relative ratios and correlations between isoforms in CSF has not been extensively studied. Although CSF and serum NF-L is known to increase in several neurodegenerative diseases $[49,50]$ including FTD, NF-M has to our knowledge not been investigated in the context of FTD before. However, high CSF levels of NF-M has previously been reported in stroke patients [51] and using the same NF-M antibodies as in this study, high levels of NF-M were observed in plasma of ALS patients [52].

Promising patterns were also observed for other proteins, such as NPTXR, TMEM132D and PDYN. NPTXR is a receptor protein predominantly expressed in the brain [53]. It is part of the neuronal pentraxin family and has been suggested as a marker for both $\mathrm{AD}$ and genetic FTD [34, 39]. NPTXR was recently measured by Van der Ende et al. (2019), together with VGF, and found at lower levels in FTD patients compared to noncarriers, independent of mutation group (C9orf72, GRN or MAPT) [34]. Although different mutation groups could not be compared in our study, we also observed lower levels of NPTXR in patients. TMEM132D is a transmembrane protein also highly expressed in the brain [54]. Its function is still largely unknown but it has been suggested to serve as a cell surface marker for oligodendrocytes [55], and more recently, to possess celladhesion functions [56]. Although genetic variants in TMEM132D have been associated with primary psychiatric disorders [57], this is to our knowledge, the first report of TMEM132D in relation to FTD, but TMEM132D was one of the proteins for which the results from the first cohort could not be replicated with significance. However, as both cohorts show concordant trends, we still believe TMEM132D to be an interesting protein to be further explored in the context of FTD. PDYN is the precursor of dynorphins, a group of endogenous opioid peptides that has implications for pain and addiction [58]. Certain gene variants of $P D Y N$ have been associated to episodic memory performance [59] and others have been shown to cause spinocerebellar ataxia type 23 [60]. Yakovleva et al. (2007) reported upregulated levels of dynorphin A (a cleavage product of PDYN), in AD patients but no change in levels of PDYN was observed [61]. Knock-out of PDYN expression was suggested to protect against age related cognitive decline in mice, but its importance in human dementia is still unknown [62].

As this is a pilot study, we acknowledge several limitations. The sample size is small which limits the statistical computations. For example, comparisons between different genetic groups were not possible nor were correlations to time to expected onset in the PMC group ( $n=$ 16). The presence of motor neuron symptoms could not be assessed separately as they were found in only four cases. Also, only four of the 29 FTD cases were mutation carriers, compared to all of the PMC which might influence the comparisons between these two groups. Since age is the most significant risk factor for dementia, agerelated changes in CSF protein concentration is a highly relevant topic for studies of dementia [63-65]. We observed significant age effects on eight of the 26 proteins found to be different in FTD patients compared to unaffected individuals, in any of the two cohorts. Hence, for these eight proteins, we cannot rule out that the differences in protein levels observed between the groups could be due to age rather than diagnosis, or a combination of both. Five of the eight proteins were also among those for which the differences between unaffected individuals and FTD could not be replicated in the second cohort. There could be many reasons why the results could not be replicated, such as sample size and heterogeneity between the two control groups in the patient population, or that there are no generalisable differences between FTD and unaffected individuals for these proteins. Since the control group in the second cohort did not contain any presymptomatic mutation carriers, nothing can be said about the subgroup comparisons. Limitations commonly associated with antibodies such as off-target binding, also applies in this study, and all antibodies have undergone technical validation within the Human Protein Atlas project. The NF-M antibodies have been extensively investigated and the developed sandwich assay shows that both antibodies (HPA023138 and HPA022845) bind NF-M, as previously verified by PRM-mass spectrometry in CSF [66]. Nevertheless, with the setup used here we cannot fully exclude that some 
reactivity towards either NF-L or NF-H could be present in addition to binding of NF-M. The semi-quantitative nature of the SBA assay could be viewed as a limitation since no definite concentrations are obtained. However, it has previously been shown that the protein levels acquired by the use of suspension bead arrays can be reproduced using other methods [28, 52, 66, 67].

\section{Conclusions}

Overall, our results show that CSF protein profiles differ between bvFTD, PPA, PMC and NC, and that the largest differences are found between bvFTD and NC. Biomarker research in FTD has previously focused primarily on analysis of single proteins and there are limited results on combinations of protein levels, for example NF$\mathrm{L}$ and tau [19]. Here, we demonstrate that it might be possible to separate healthy individuals from patients with FTD by combining the protein levels of VGF, TN-R and NF-M. Promising patterns were also found for a number of other proteins, such as NPTXR, TMEM132D and PDYN, which need to be explored further. We are currently in the process of validating the results in a larger cohort from the GENetic Frontotemporal Dementia Initiative (GENFI) [23], where we include both CSF and plasma samples.

Both clinical phenotype, neuropathology and genetic findings are highly heterogeneous in FTD. With advancements in computational data analysis, we have the possibility to study complex diseases by searching for patterns, as opposed to limiting the analysis to single biomarkers. The results from the PCA and cluster analyses advocate the future use of multivariate methods in dementia research which we plan to incorporate in the follow-up study. Although validation in a larger cohort is necessary to confirm our findings and approach biomarker applications in a clinical setting, we believe the results presented here could be a first step towards highly needed new biomarkers for FTD.

\section{Supplementary information}

Supplementary information accompanies this paper at https://doi.org/10. 1186/s40035-020-00198-y.

Additional file 1: Supplementary Table 1. List of 70 proteins included in statistical analysis. Sorted by $p$-value (lowest to highest).

Supplementary Table 2. $P$-values of age effect from generalized linear models. Sorted by order of Table 2. Supplementary Table 3. Table of unadjusted $p$-values for group separations in the second cohort. Sorted by order of Table 2. Supplementary Table 4. Antibodies used for development of NF-M sandwich assay.

Additional file 2: Supplementary Figure 1. CSF levels of proteins in Table 2. Statistically significant differences ( $p$-values) are found in Table 2. NC - Non-carriers, PMC - Presymptomatic mutation carriers, PPA - Primary progressive aphasia, bvFTD - Behavioural variant FTD.

Additional file 3: Supplementary Figure 2. Validation of NF-M antibody binding. (A) Detection of NF-M with HPA022845 as capture antibody and 20,664-1-AP as detection antibody. No cross-reactivity with antibodies targeting NF-L or NF-H was observed. (B) Detection of NF-M with HPA022845 as capture antibody and 13-0700 as detection antibody. No cross-reactivity with antibodies targeting NF-L or NF-H was observed. (C) Detection of NF-M with HPA023138 as capture antibody and 34-1000 as detection antibody. No cross-reactivity with antibodies targeting NF-L or NF-H was observed. (D-F) Comparison between sandwich assay data and single-binder data. $\mathrm{Rho}_{(\mathrm{D})}=0.85, \mathrm{P}_{(\mathrm{D})}=1 \mathrm{E}^{-7}, \operatorname{rho}_{(\mathrm{E})}=0.86, \mathrm{P}_{(\mathrm{E})}=1 \mathrm{E}^{-7}$, $\mathrm{rho}_{(\mathrm{F})}=0.82, \mathrm{p}_{(\mathrm{F})}=1 \mathrm{E}^{-6}$.

Additional file 4: Supplementary Figure 3. Correlation between NFM assays. (A) Correlation between HPA022845 and HPA023138 singlebinder data. (B) Correlation between HPA022845 sandwich assays. HPA022845 was used as capture antibody together with two different detection antibodies, 20,664-1-AP and 13-0700. (C) Correlation between one HPA22845 sandwich assay and HPA023138 sandwich assay. HPA022845 was used as capture antibody together with 20,664-1-AP as detection antibody, and HPA023138 was used as capture antibody together with 34-1000 as detection antibody.

Additional file 5: Supplementary Figure 4. Antibodies used for development of NF-M sandwich assay aligned to the neurofilament amino acid sequences. The neurofilaments are shown in green and the size of the domains (head, rod and tail) are displayed at the top. The highly conserved rod domain is highlighted in grey. Position and length of the amino acid sequences used to generate the antibodies are shown in blue and the exact amino acid positions are given in brackets, if known. Antibody 13-1300 targets all three neurofilaments. The smallest epitope identified for HPA022845 corresponds to amino acids $746-749$ [50].

\section{Abbreviations}

ACT: Alpha-1-antichymotrypsin; AD: Alzheimer's disease; ALS: Amyotrophic lateral sclerosis; ApoA-l: Apolipoprotein A-l; bvFTD: Behavioural variant FTD; CDH8: Cadherin-8; CHL1: Neural cell adhesion molecule L1-like protein; CLSTN1: Calsyntenin-1; CSF: Cerebrospinal fluid; CV: Coefficient of variance; FDR: False discovery rate; FTD: Frontotemporal dementia; GENFI: GENetic frontotemporal dementia initiative; GRN: Progranulin; HPA: Human protein atlas project; LCCC: Lin's concordance coefficient; LRG: Leucine-rich alpha-2glycoprotein; MAPT: Microtubule-associated protein tau; MFI: Median fluorescence intensity; MMSE: Mini-mental State examination; NBB: Netherlands institute for neuroscience; NC: Non-carriers; NCAN: Neurocan core protein; NF-H: Neurofilament heavy chain; NFL: Neurofilament light chain; NF-M: Neurofilament medium polypeptide; NINCDS-ADRDA: National institute of neurological and communicative disorders and stroke and the Alzheimer's disease and related disorders association; NP1: Neuronal pentraxin-1; NPTXR: Neuronal pentraxin receptor; PBS-T: Phosphate buffered saline with 0.05\% Tween ${ }^{\circledR} 20$; PCA: Principal component analysis; PDYN: Prodynorphin; PMC: Presymptomatic mutation carriers; PNFA: Progressive non-fluent aphasia; PPA: Progressive primary aphasia; SAPE: Streptavidin coupled fluorophore; SD: Semantic dementia; TMEM132D: Transmembrane protein 132D; TN-R: Tenascin-R; VCP: Valosin containing protein; VGF: Neurosecretory protein VGF

\section{Acknowledgements}

The authors wish to thank all the patients and caregivers who participated in the study. The authors also want to thank all the funders and donors who have supported this project.

\section{Authors' contributions}

J.R. and L.Ö. contributed to the study design, data acquisition, statistical analysis, interpretation, drafting and editing of the manuscript. A.U. contributed to the study design, statistical analysis, interpretation and editing of the manuscript. J.O. and S.B. contributed to the study design, data acquisition, interpretation and editing of the manuscript. K.K., M.I., L.K. and M.U. contributed to the study design and editing of the manuscript. A. M, C.G. and P.N. contributed to the study design, interpretation and editing of the manuscript. The author(s) read and approved the final manuscript.

\section{Funding}

This study was supported by grants from the Swedish FTD initiative funded by the Schörling Family Foundation and the KTH Center for Applied Precision Medicine (KCAP) funded by the Erling-Persson Family Foundation. 
$C G, L O ̈$ and $A U$ were further supported by grants from JPND Prefrontals Swedish Research Council (VR) 529-2014-7504, Swedish Research Council (VR) 2015-02926, Swedish Research Council (VR) 2018-02754, Swedish Brain Foundation, Swedish Alzheimer Foundation, Stockholm County Council ALF, Karolinska Institutet Doctoral Funding and StratNeuro, Swedish Demensfonden. The authors acknowledge support from the National Genomics Infrastructure in Stockholm/Uppsala funded by Science for Life Laboratory, the Knut and Alice Wallenberg Foundation and the Swedish Research Council, and SNIC/Uppsala Multidisciplinary Center for Advanced Computational Science for assistance with massively parallel sequencing and access to the UPPMAX computational infrastructure. Open access funding provided by Royal Institute of Technology.

\section{Availability of data and materials}

The datasets generated and analysed during the current study are available from the corresponding authors upon request.

\section{Ethics approval and consent to participate}

The study was approved by the Regional Ethical Review Board, Stockholm, Sweden (registration numbers: 2017/834-31/1, 2012/1611-31/3, 2013/1563$32,2017 / 2097-32)$ and the Regional Ethical Review Board in Uppsala, Sweden (registration numbers: 2005-244, Ö 48-2005; 2005-11-02, 2006-0130, 2011/044; 2011-02-23).

\section{Consent for publication}

Not applicable.

\section{Competing interests}

The authors declare no competing interest relevant to the work conducted in the presented study.

\section{Author details}

'Division of Affinity Proteomics, Department of Protein Science, KTH Royal Institute of Technology, SciLifeLab, Tomtebodavägen 23 A, Alpha 2, 17165 Solna, Stockholm, Sweden. ${ }^{2}$ Swedish FTD Initiative, Stockholm, Sweden. ${ }^{3}$ Division of Neurogeriatrics, Centre for Alzheimer Research, Department of Neurobiology, Care Sciences and Society, Karolinska Institutet, 17164 Solna, Sweden. ${ }^{4}$ Unit for hereditary dementias, Theme Aging, Karolinska University Hospital, Stockholm, Sweden. ${ }^{5}$ Department of Medical Sciences, Clinical Chemistry, Uppsala University, Uppsala, Sweden. ${ }^{6}$ Department of Public Health and Caring Sciences, Geriatrics, Uppsala University, Uppsala, Sweden. 7Department of Neuroscience, Karolinska Institutet, Solna, Sweden.

\section{Received: 27 November 2019 Accepted: 7 May 2020}

\section{Published online: 23 June 2020}

\section{References}

1. Rascovsky K, Hodges JR, Knopman D, Mendez MF, Kramer JH, Neuhaus J, et al. Sensitivity of revised diagnostic criteria for the behavioural variant of frontotemporal dementia. Brain [Internet] 2011;134(9):2456-2477. Available from: https://academic.oup.com/brain/article-lookup/doi/10.1093/brain/awr179.

2. Gorno-Tempini ML, Hillis AE, Weintraub S, Kertesz A, Mendez M, Cappa SF, et al. Classification of primary progressive aphasia and its variants. Neurol Int 2011;76(11):1006-1014. Available from: http://www.neurology.org/cgi/doi/1 0.1212/WNL.0b013e31821103e6.

3. Lomen-Hoerth C, Murphy J, Langmore S, Kramer JH, Olney RK, Miller B. Are amyotrophic lateral sclerosis patients cognitively normal? Neurology. 2003; 60(7):1094-7.

4. Bang J, Spina S, Miller BL. Frontotemporal dementia. Lancet. 2015; 386(10004):1672-82.

5. Hodges JR, Patterson K, Ward R, Garrard P, Bak T, Perry R, et al. The differentiation of semantic dementia and frontal lobe dementia (temporal and frontal variants of frontotemporal dementia) from early Alzheimer's disease: a comparative neuropsychological study. Neuropsychology. 1999; 13(1);31-40

6. Rohrer JD, Beck J, Isaacs AM, Authier A, Warren JD, Mead S. The heritability and genetics of frontotemporal lobar degeneration 2009;1451-1456.

7. Hutton M, Lendon CL, Rizzu P, Baker M, Froelich S, Houlden H, et al. Association of missense and 5 '-splice-site mutations in tau with the inherited dementia FTDP-17. Nature. 1998;393(6686):702-5 Available from: http://www.nature.com/articles/31508.
8. Baker M, Mackenzie IR, Pickering-Brown SM, Gass J, Rademakers R, Lindholm $\mathrm{C}$, et al. Mutations in progranulin cause tau-negative frontotemporal dementia linked to chromosome 17. Nature [Internet]. 2006;442(7105):916-9 Available from: http://www.nature.com/articles/nature05016.

9. Cruts M, Gijselinck I, van der Zee J, Engelborghs S, Wils H, Pirici D, et al. Null mutations in progranulin cause ubiquitin-positive frontotemporal dementia linked to chromosome 17q21. Nature. 2006;442(7105):920-4 Available from: http://www.nature.com/articles/nature05017.

10. DeJesus-Hernandez M, Mackenzie IR, Boeve BF, Boxer AL, Baker M, Rutherford NJ, et al. Expanded GGGGCC Hexanucleotide repeat in noncoding region of C9ORF72 causes chromosome 9p-linked FTD and ALS. Neuron. 2011;72(2):245-56 Available from: https://linkinghub.elsevier.com/ retrieve/pii/S0896627311008282.

11. Renton AE, Majounie E, Waite A, Simón-Sánchez J, Rollinson S, Gibbs JR, et al. A Hexanucleotide repeat expansion in C9ORF72 is the cause of chromosome 9p21-linked ALS-FTD. Neuron. 2011;72(2):257-68 Available from: https://linkinghub.elsevier.com/retrieve/pii/S0896627311007975.

12. Öijerstedt L, Chiang H-H, Björkström J, Forsell C, Lilius L, Lindström A-K, et al. Confirmation of high frequency of C9orf72 mutations in patients with frontotemporal dementia from Sweden. Neurobiol Aging [Internet]. 2019;84: 241.e21-241.e25. Available from: https://linkinghub.elsevier.com/retrieve/pii/ S0197458019300879. Cited 4 Sep 2019.

13. van der Zee J, Gijselinck I, Dillen L, Van Langenhove T, Theuns J, Engelborghs S, et al. A pan-European study of the C9orf72 repeat associated with FTLD: geographic prevalence, genomic instability, and intermediate repeats. Hum Mutat. 2013 Feb [cited 2018 Jun 6];34(2):363-373. Available from: http://doi. wiley.com/10.1002/humu.22244.

14. Van Mossevelde S, Engelborghs S, van der Zee J, Van Broeckhoven C. Genotype-phenotype links in frontotemporal lobar degeneration. Nat Rev Neurol 201818 [cited 2019 Mar 26];14(6):363-378. Available from: http:// www.nature.com/articles/s41582-018-0009-8.

15. Scherling CS, Hall T, Berisha F, Klepac K, Karydas A, Coppola G, et al. Cerebrospinal fluid neurofilament concentration reflects disease severity in frontotemporal degeneration. Ann Neurol. 2014;75(1):116-26.

16. Meeter LH, Kaat LD, Rohrer JD, Van Swieten JC. Imaging and fluid biomarkers in frontotemporal dementia. Nat Rev Neurol. 2017;13(7):406-19.

17. Hu WT, Chen-Plotkin A, Grossman M, Arnold SE, Clark CM, Shaw LM, et al. Novel CSF biomarkers for frontotemporal lobar degenerations. Neurology. 2010;75(23):2079-86.

18. Rivero-Santana A, Ferreira D, Perestelo-Perez L, Westman E, Wahlund L-O, Sarria A, et al. Cerebrospinal fluid biomarkers for the differential diagnosis between Alzheimer's disease and Frontotemporal lobar degeneration: systematic review, HSROC analysis, and confounding factors. J Alzheimers Dis. 2017;55(2):625-44

19. Meeter LH, Dopper EG, Jiskoot LC, Sanchez-Valle R, Graff C, Benussi L, et al. Neurofilament light chain: a biomarker for genetic frontotemporal dementia. Ann Clin Transl Neurol. 2016 Aug;3(8):623-36.

20. Skillback T, Farahmand B, Bartlett JW, Rosen C, Mattsson N, Nagga K, et al. CSF neurofilament light differs in neurodegenerative diseases and predicts severity and survival. Neurology. 2014;83(21):1945-53.

21. Bridel $C$, van Wieringen WN, Zetterberg H, Tijms BM, Teunissen CE, AlvarezCermeño JC, et al. Diagnostic value of cerebrospinal fluid Neurofilament light protein in neurology: a systematic review and meta-analysis. JAMA Neurol. 2019;76(9):1035-48.

22. Rohrer JD, Warren JD, Fox NC, Rossor MN. Presymptomatic studies in genetic frontotemporal dementia. Revue Neurologique (Paris); 2013;169(10): 820-4.

23. Rohrer JD, Nicholas JM, Cash DM, Van SJ, Dopper E, Jiskoot L, et al. Presymptomatic cognitive and neuroanatomical changes in genetic frontotemporal dementia in the Genetic Frontotemporal dementia Initiative ( GENFI ) study. Cross-Sectional Anal. 2015;4422(14)):1-10.

24. Schwenk JM, Gry M, Rimini R, Uhlén M, Nilsson P. Antibody suspension bead arrays - an application for serum and plasma analysis within antibody proteomics. J Proteome Res. 2008;7:3168-79.

25. Pin E, Sjoberg R, Andersson E, Hellstrom C, Olofsson J, Jernbom Falk A, et al. Array-based profiling of proteins and autoantibody repertoires in CSF. Methods Mol Biol. 2019;2044:303-18.

26. Remnestål J, Just D, Mitsios N, Fredolini C, Mulder J, Schwenk JM, et al. CSF profiling of the human brain enriched proteome reveals associations of neuromodulin and neurogranin to Alzheimer's disease. Proteomics - Clin Appl. 2016;10(12):1242-53. 
27. Häggmark A, Byström S, Ayoglu B, Qundos U, Uhlén M, Khademi M, et al. Antibody-based profiling of cerebrospinal fluid within multiple sclerosis. Proteomics. 2013;13(15):2256-67.

28. Haussler RS, Bendes A, Iglesias M, Sanchez-Rivera L, Dodig-Crnkovic T, Bystrom S, et al. Systematic development of Sandwich immunoassays for the plasma Secretome. Proteomics. 2019 Aug;19(15):e1900008.

29. Core R, Team R. A language and environment for statistical computing. In: R Foundation For Statistical Computing [Internet]. Vienna, Austria: R Foundation For Statistical Computing; 2018. Available from: https://www.rproject.org/.

30. Benjamini $Y$, Hochberg $Y$. Controlling the false discovery rate: a practical and powerful approach to multiple testing. J R Stat Soc Ser B. 1995;57:289300.

31. Bateman RJ, Xiong C, Benzinger TLS, Fagan AM, Goate A, Fox NC, et al. Clinical and biomarker changes in dominantly inherited alzheimer's disease. N Engl J Med. 2012;367(9);795-804.

32. Riedl MS, Braun PD, Kitto KF, Roiko SA, Anderson LB, Honda CN, et al. Proteomic analysis uncovers novel actions of the neurosecretory protein VGF in nociceptive processing. J Neurosci. 2009;29(42):13377-88.

33. Sato H, Fukutani $Y$, Yamamoto $Y$, Tatara E, Takemoto M, Shimamura K, et al. Thalamus-derived molecules promote survival and dendritic growth of developing cortical neurons. J Neurosci. 2012;32(44):15388-402.

34. van der Ende EL, Meeter LH, Stingl C, van Rooij JGJ, Stoop MP, Nijholt DAT, et al. Novel CSF biomarkers in genetic frontotemporal dementia identified by proteomics. Ann Clin Transl Neurol. 2019;6(4):698-707.

35. Rüetschi U, Zetterberg H, Podust VN, Gottfries J, Li S, Hviid Simonsen A, et al. Identification of CSF biomarkers for frontotemporal dementia using SELDI-TOF. Exp Neurol. 2005;196(2):273-81.

36. Khoonsari PE, Shevchenko G, Herman S, Remnestal J, Giedraitis V, Brundin R, et al. Improved differential diagnosis of Alzheimer's disease by integrating ELISA and Mass spectrometry-based cerebrospinal fluid biomarkers. J Alzheimers Dis. 2019;67(2):639-51.

37. Duits FH, Brinkmalm G, Teunissen CE, Brinkmalm A, Scheltens P, Van der Flier WM, et al. Synaptic proteins in CSF as potential novel biomarkers for prognosis in prodromal Alzheimer's disease. Alzheimers Res Ther. 2018 15; 10(1):5. Available from: https://alzres.biomedcentral.com/articles/10.1186/ s13195-017-0335-x.

38. Brinkmalm G, Sjodin S, Simonsen AH, Hasselbalch SG, Zetterberg $H$, Brinkmalm A, et al. A parallel reaction monitoring mass spectrometric method for analysis of potential CSF biomarkers for alzheimer's disease. Proteomics Clin Appl. 2018;12(1);1700131:1-13.

39. Hendrickson RC, Lee AYH, Song Q, Liaw A, Wiener M, Paweletz CP, et al. High resolution discovery proteomics reveals candidate disease progression markers of Alzheimer's disease in human cerebrospinal fluid. PLoS One. 2015;10(8):e0135365

40. Galtrey CM, Kwok JCF, Carulli D, Rhodes KE, Fawcett JW. Distribution and synthesis of extracellular matrix proteoglycans, hyaluronan, link proteins and tenascin-R in the rat spinal cord. Eur J Neurosci. 2008;27(6):1373-90.

41. Wintergerst ES, Rathjen FG, Schwaller B, Eggli P, Celio MR. Tenascin-R associates extracellularly with parvalbumin immunoreactive neurones but is synthesised by another neuronal population in the adult rat cerebral cortex. J Neurocytol. 2001;30(4):293-301.

42. Bukalo O, Schachner M, Dityatev A. Modification of extracellular matrix by enzymatic removal of chondroitin sulfate and by lack of tenascin- $R$ differentially affects several forms of synaptic plasticity in the hippocampus. Neuroscience. 2001;104(2):359-69.

43. Probstmeier R, Stichel CC, Muller HW, Asou H, Pesheva P. Chondroitin sulfates expressed on oligodendrocyte-derived tenascin-R are involved in neural cell recognition. Functional implications during CNS development and regeneration. J Neurosci Res. 2000;60(1):21-36.

44. Manavalan A, Mishra M, Feng L, Sze SK, Akatsu H, Heese K. Brain site-specific proteome changes in aging-related dementia. Exp Mol Med [Internet] 2013; 45(9):e39-e17. Available from: https://doi.org/10.1038/emm.2013.76.

45. Freitag S, Schachner M, Morellini F. Behavioral alterations in mice deficient for the extracellular matrix glycoprotein tenascin-R. Behav Brain Res. 2003; 145(1-2):189-207.

46. Montag-Sallaz M, Montag D. Severe cognitive and motor coordination deficits in tenascin-R-deficient mice. Genes, Brain Behav. 2003;2(1):20-31.

47. Yuan A, Rao MV, Veeranna, Nixon RA. Neurofilaments and neurofilament proteins in health and disease. Cold Spring Harb Perspect Biol. 2017;9(4); a018309:1-24.
48. Janmey PA, Leterrier JF, Herrmann $\mathrm{H}$. Assembly and structure of neurofilaments. Curr Opin Colloid Interface Sci. 2003;8:145-55.

49. Gattringer T, Otto M, Teunissen CE, Comabella M, Blennow K, Kuhle J, et al. Neurofilaments as biomarkers in neurological disorders. Nat Rev Neurol. 2018;14(10):577-89.

50. Oeckl P, Weydt P, Thal DR, Weishaupt JH, Ludolph AC, Otto M. Proteomics in cerebrospinal fluid and spinal cord suggests UCHL1, MAP 2 and GPNMB as biomarkers and underpins importance of transcriptional pathways in amyotrophic lateral sclerosis. Acta Neuropathol. 2020;139(1):119-34.

51. Martinez-Morillo E, Childs C, Garcia BP, Alvarez Menendez FV, Romaschin $A D$, Cervellin G, et al. Neurofilament medium polypeptide (NFM) protein concentration is increased in CSF and serum samples from patients with brain injury. Clin Chem Lab Med. 2015 Sep;53(10):1575-84.

52. Häggmark A, Mikus M, Mohsenchian A, Hong M-G, Forsstrom B, Gajewska B, et al. Plasma profiling reveals three proteins associated to amyotrophic lateral sclerosis. Ann Clin Transl Neurol. 2014 Aug;1(8):544-53.

53. The Human Protein Atlas. NPTXR Tissue Expression [Internet]. Available from: https://www.proteinatlas.org/ENSG00000221890-NPTXR/tissue. Cited 16 Jan 2020.

54. The Human Protein Atlas. TMEM132D Tissue Expression [Internet]. Available from: https://www.proteinatlas.org/ENSG00000151952-TMEM132D/tissue. Cited 16 Jan 2020

55. Nomoto H, Yonezawa T, Itoh K, Ono K, Yamamoto K, Oohashi T, et al. Molecular cloning of a novel transmembrane protein MOLT expressed by mature oligodendrocytes. J Biochem. 2003;134(2):231-8.

56. Sanchez-Pulido L, Ponting CP. TMEM132: an ancient architecture of cohesin and immunoglobulin domains define a new family of neural adhesion molecules. Bioinformatics. 2018;34(5):721-4.

57. Erhardt A, Akula N, Schumacher J, Czamara D, Karbalai N, Müller-Myhsok B, et al. Replication and meta-analysis of TMEM132D gene variants in panic disorder. Transl Psychiatry. 2012;2(9):e156 [cited 2019 Sep 4] Available from: http://www.ncbi.nlm.nih.gov/pubmed/22948381.

58. Schwarzer C. 30 years of dynorphins--new insights on their functions in neuropsychiatric diseases. Pharmacol Ther. 2009;123(3):353-70.

59. Kolsch H, Wagner M, Bilkei-Gorzo A, Toliat MR, Pentzek M, Fuchs A, et al. Gene polymorphisms in prodynorphin (PDYN) are associated with episodic memory in the elderly. J Neural Transm. 2009;116(7):897-903.

60. Fawcett K, Mehrabian M, Liu Y-T, Hamed S, Elahi E, Revesz T, et al. The frequency of spinocerebellar ataxia type 23 in a UK population. J Neurol. 2013;260(3):856-9.

61. Yakovleva T, Marinova Z, Kuzmin A, Seidah NG, Haroutunian V, Terenius L, et al. Dysregulation of dynorphins in Alzheimer disease. Neurobiol Aging. 2007;28(11):1700-8.

62. Menard C, Herzog H, Schwarzer C, Quirion R. Possible role of dynorphins in Alzheimer's disease and age-related cognitive deficits. Neurodegener Dis. 2014;13(2-3):82-5.

63. Chen $C P C$, Chen RL, Preston JE. The influence of ageing in the cerebrospinal fluid concentrations of proteins that are derived from the choroid plexus, brain, and plasma. Exp Gerontol [Internet] 2012;47(4):323-328. Available from: https://doi.org/10.1016/j.exger.2012.01.008.

64. Zhang J, Goodlett DR, Peskind ER, Quinn JF, Zhou Y, Wang Q, et al. Quantitative proteomic analysis of age-related changes in human cerebrospinal fluid. Neurobiol Aging. 2005;26(2):207-27.

65. Baird GS, Nelson SK, Keeney TR, Stewart A, Williams S, Kraemer S, et al. Agedependent changes in the cerebrospinal fluid proteome by slow off-rate modified aptamer array. Am J Pathol 2012;180(2):446-456. Available from: https://doi.org/10.1016/j.ajpath.2011.10.024.

66. Andersson A, Remnestål J, Nellgård B, Vunk H, Kotol D, Edfors F, et al. Development of parallel reaction monitoring assays for cerebrospinal fluid proteins associated with Alzheimer's disease. Clin Chim Acta . 2019; 494(march):79-93. Available from: https://doi.org/10.1016/j.cca.2019.03.243.

67. Qundos U, Hong MG, Tybring G, Divers M, Odeberg J, Uhlen M, et al. Profiling post-centrifugation delay of serum and plasma with antibody bead arrays. J Proteomics [Internet]. 2013;95:46-54. Available from: https://doi.org/ 10.1016/j.jprot.2013.04.020. 